\title{
APS STORAGE RING VACUUM SYSTEM
}

R. C. Niemann, R. Benaroya, M. Choi, R. J. Dortwegt, G. A. Goeppner, J. Gonczy, C. Krieger, J. Howell, R. W. Nielsen, B. Roop, R. B. Wehrle Argonne National Laboratory, Argonne, IL 60439

\begin{abstract}
The Advanced Photon Source synchrotron radiation facility, under construction at the Argonne National Laboratory, incorporates a large ring for the storage of $7 \mathrm{GeV}$ positrons for the generation of photon beams for the facililty's experimental program. The Storage Ring's $1104 \mathrm{~m}$ circumference is divided into 40 functional sectors. The sectors include vacuum, beam transport, control, acceleration and insertion device components. The vacuum system, which is designed to operate at a pressure of 1 nTorr, consists of 240 connected sections, the majority of which are fabricated from an aluminum alloy extrusion. The sections are equipped with distributed $\mathrm{NeG}$ pumping, photon absorbers with lumped pumping, beam position monitors, vacuum diagnostics and valving. The details of the vacuum system design, selected results of the development program and general construction plans are presented.
\end{abstract}

\section{INTRODUCTION}

The Advanced Photon Source (APS) incorporates a 7-GeV positron storage ring approximately $1104 \mathrm{~m}$ in cirsumference. The storage ring vacuum system is designed to maintain a pressure of 1 nTorr or less with a circulating current of 300 $m A$ to enable beam lifetimes of greater than 10 hours. 1,2,3 The vacuum system employs Non-evaporable Getter (NeG) strips as the primary source of distributed pumping throughout the ring. Lumped NeG modules and/or ion pumps are used at photon absorber locations. Significant parameters of the Storage Ring Vacuum System are listed in Table 1. 
Table I Storage Ring Vacuum System Parameters

$\begin{array}{lll}\text { CIRCUMFERENCE } & 1104 & \mathrm{~m} \\ \text { FORMED SHAPE } & 39.896 & \mathrm{~m} \text { INSIDE BEND RADIUS } \\ \text { VACIJUM CHAMBER MATERIAL } & 6063 \text { ALUMINUM EXTRUSION } \\ & 2219 \text { ALUMINUM FLANGES AND PORTS } \\ \text { HORIZONTAL APERTURE (BEAM CHAMBER) } & 85 & \mathrm{~mm} \\ \text { VERTICAL APERTURE (BEAM CHAMBER) } & 42 & \mathrm{~mm} \\ \text { CHAMBER WALL THICKNESS } & 12 & \mathrm{~mm} \\ \text { OUTGASSING LOAD AFTER 150 A-h } & 3.77 \times 10^{-5} & \text { Torr l/s } \\ \text { POSITRON BEAM LIFETIME } & >10 & \mathrm{~h} \\ \text { BEAM-ON OPERATING PRESSURE } & 1 & \mathrm{nTorr} \text { or less (average) } \\ & & \text { afler 100 A-h }\end{array}$

\section{STORAGE RING SECTORS}

The storage ring is divided into forty $27.6 \mathrm{~m}$ long sectors. Each sector consists of 6 sections, 5 of which contain magnetic elements for beam transport with the other section containing either of (3), diagnostics (1), injection (1), abort (1) or insertion devices (34). A total of 69 experimental facility photon beams are possible, 34 of which are generated by insertion devices and 35 by bending magnets.

The storage ring sector layout is as shown in Figure 1. Sector components include the crotch photon absorbers and pumps at the end of the two dipole curved chambers. The straight chambers contain downstream end absorbers and pumps. The largest gas desorption loads are located at the photon absorbers and are pumped locally by high capacity pumps. Large lumped ion and lumped NeG pumps are mounted at these locations in order to capture the bulk of the desorbed gases. Significant amounts of these and other photon and thermal desorbed gases permeate the chamber and are subsequently pumped by the distributed NeG pumps located in the pump antechamber. The distributed NeG pumping strips are essentially continuous in the chambers and are shown in Figure 2. 

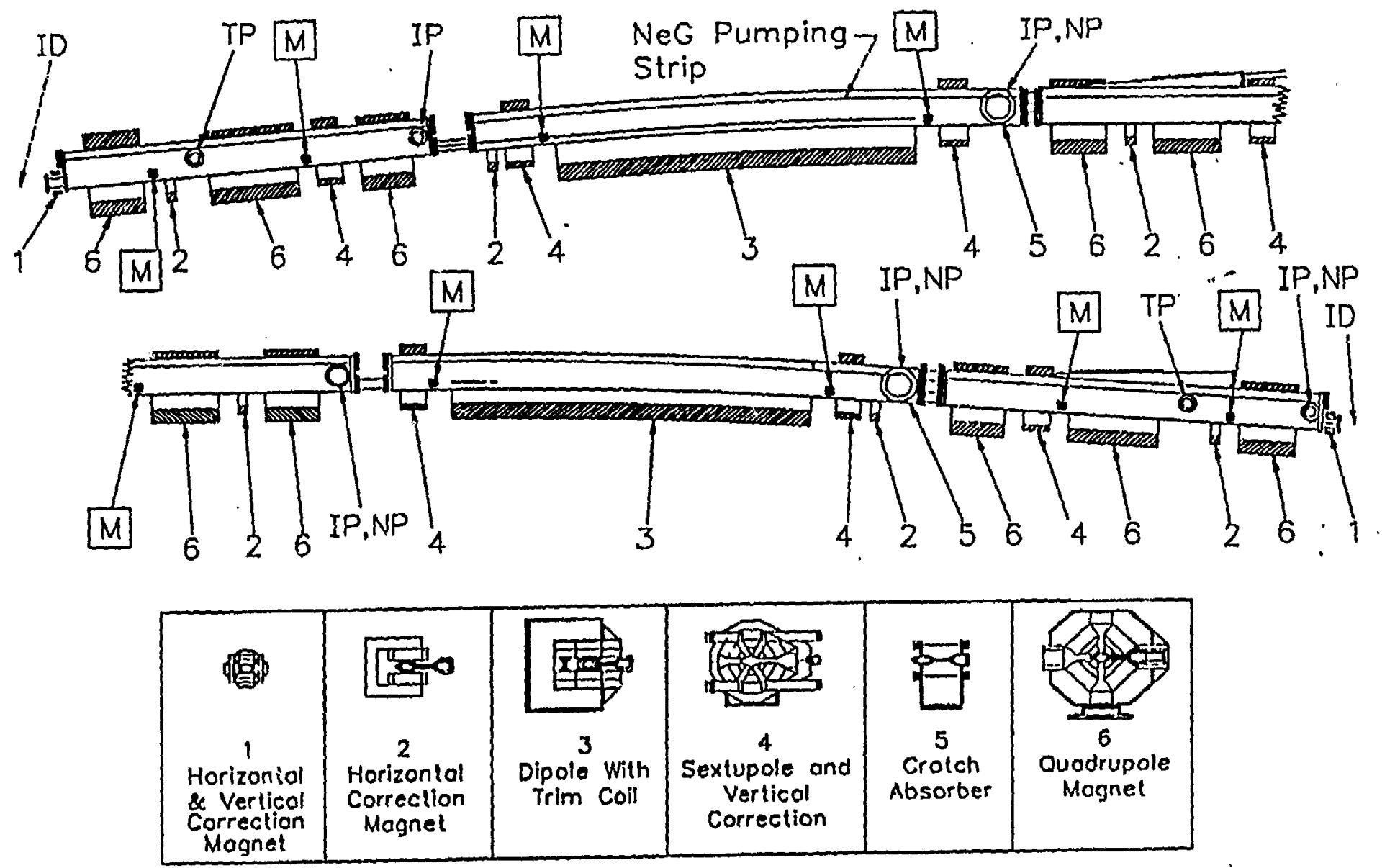
$M]=$ Beom Position Monitor
IP $=$ Lumped Ion Pump
$T P=$ Turbomolecular Pump
$N P=$ Lumped Neg Pump

Figure 1

APS STORAGE RING SECTOR LAYOUT 


\section{VACUUM CHAMBER}

The vacuum chamber consists of three main regions, the positron beam chamber, the pump antechamber, connected by the photon beam channel. The 10 $\mathrm{mm}$ photon beam channel gap is high enough for the photon beams to pass through to the extraction channel, but narrow enough so that if leakage is negligible. The antechamber entraps the outgassing that permeates from the absorber locations. The high-speed pumping in the antechamber, i.e., initially, for both upper and lower pumping strips is $270 \mathrm{l} / \mathrm{sm}$ for $\mathrm{CO}$ and $650 \mathrm{l} / \mathrm{sm}$ for $\mathrm{H}_{2}$, assures efficient removal of both photon and thermal desorbed gases. The enlarged cross-section of the pump antechamber improves the conductance of desorbed gases to the pumping surface of the NeG strips.

The chamber is a 6063 T5 aluminum extrusion. It contains water passages for cooling and bakeout. A $150^{\circ} \mathrm{C}$ bakeout is achieved with portable water-heating units. The chamber is covered with thermal insulation to reduce heat losses. The lumped pumps, gauges, valves and bellows are baked with heating electrical tapes.

The extrusions will be chemically processed after machining and prior to welding to provide a clean vacuum surface. Alkaline degreasers and etchants have been tested, and Auger analysis of the cleaned surfaces has indicated comparable results to those of Mathewson at LEP. 4,5 Since the 6063 aluminum alloy is magnesium based, the extruded surface consists of a magnesium oxide layer, which contains most of the surface contamination. The first cleaning step employs a degreasing agent as well as an agent to remove the magnesium oxide layer. Once the magnesium oxide is removed, the second step uses an etchant (potassium hydroxide) to reduce the aluminum oxide layer. A final water rinse and blow drying completes the cleaning procedure. The 2219 aluminum end flanges, utility flanges and photon exit ports are cleaned with solvents or detergents after machining and prior to welding.

The 2219 T851 aluminum end flanges are joined to the chamber extrusions with full penetration weldments. The inside surface of the weld bead is.even with the beam chamber inside surface for low if impedance. The ends of the sector each terminate in an elliptical tube beam chamber, which also has a full penetration weldment with a similar inside surface. The photon exit port block is attached by a full penetration weldment to the side of the chamber. The utility flange weldments are inside vacuum welds, either of a fillet or butt type. The large, $12^{\prime \prime}$ and $8^{\text {" }}$ diameter crotch and distributed absorber flange welds follow the contour of the extrusion. These exacting weldments are done by an automated computercontrolled TIG welding machine. 

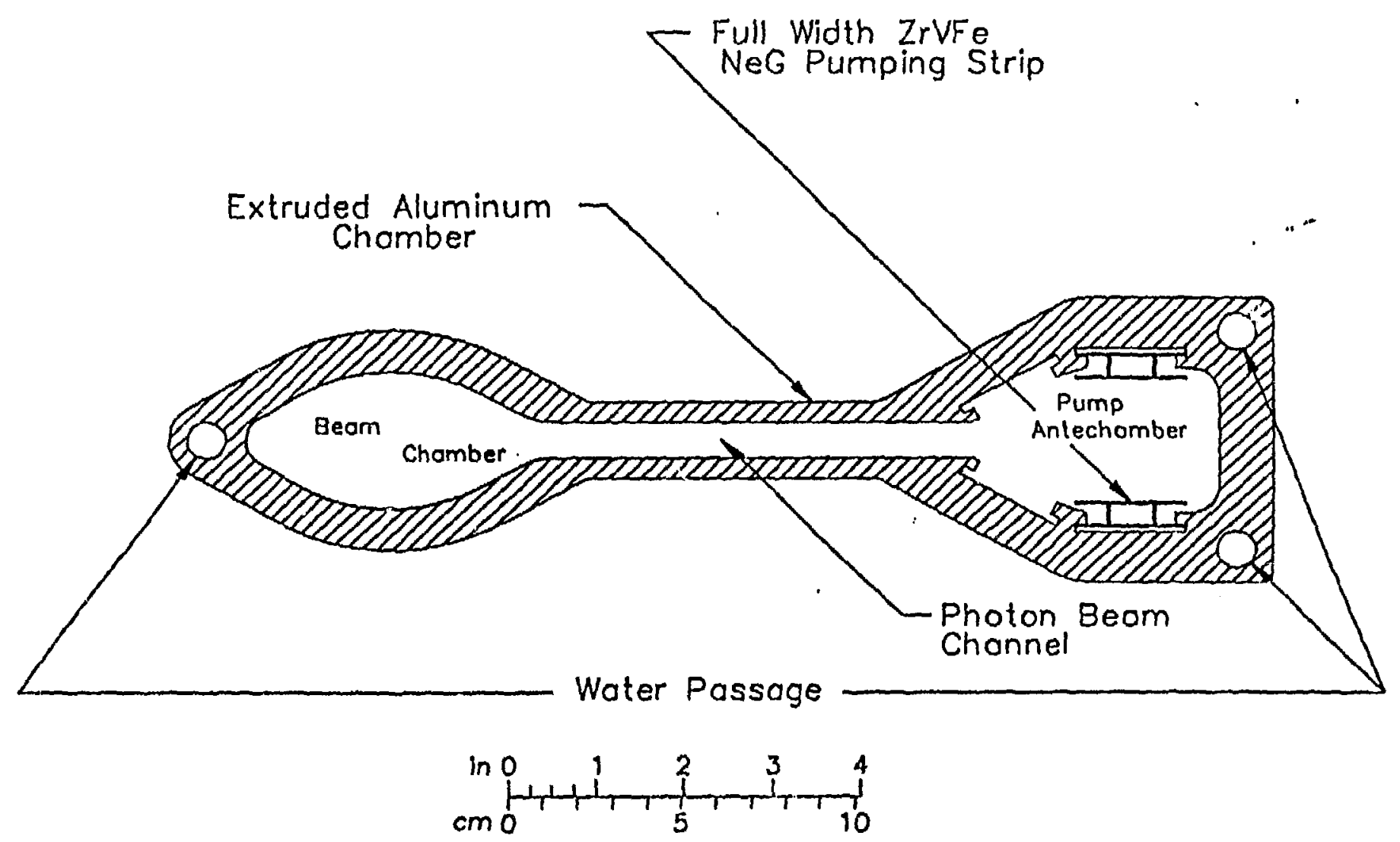

Figure 2

STORAGE RING VACUUM CHAMBER CROSS SECTION 


\section{VACUUM CHAMBER SUPPORTS}

Three supports are used per straight section. One support is rigid and does not allow chamber motion in any direstion. Its position is located approximately at the center of the section. The other two supports are each located near the ends of the chamber. Thiese two supports are leaf springs permitting chamber thermal expansion in the beam line direction during the bake cycle.

The curved sections also use three supports. Two leaf spring supports are located at the ends of the chamber to allow thermal expansion in the approximate beam direction. The center support, unlike the rigid support of a straight section, allows for the motion of a changing bend radius that occurs during the bake cycle. The midpoint of the curved section is maintained in a level position and is constrained in the beam direction. The section midpoint is allowed to move radially in the direction of its natural radial expansion by means of a pin and slot guide.

The salient aspect of both support systems is that the chambers are free to thermally expand with negligible forces piaced on them. The support system ensures that the chambers are not stressed significantly and return to their original location, size, shape and geometry after each bake cycle.

\section{PHOTON ABSORBERS}

Non-experimental facility synchrotron radiation is absorbed by photon absorbers in order to reduce the number of photons striking the vacuum chamber surfaces.

The storage ring incorporates a series of such absorbers in each sector as shown by Figure 1 and as listed in Table 2. 


\section{Table 2 Storage Ring Photon Absorbers}

LOCATION

Section 1, Downstream End

Section 2,

Downstream End

Section 2,

Downstream End

Section 3,

Downstream End

Section 4,

Downstream End

Section 4,

Downstream End

Section 5,

Downstream End

Section 6,

Downstream End

At positron beam current of $300 \mathrm{~mA}$.

NAME
End Absorber (EA1)

Crotch Absorber (C1)

13.3

Crotch Wedge Absorber (W1)

0.51

Distributed Absorber (A1)

4.32

Crotch Absorber (C2)

11.5

Crotch Wedge Absorber (W2)

3.3

Distributed Absorber (A2)

3.67

End Absorber (EA2)

1.08

Photon absorber development is continuing with emphasis placed on the design of the crotch absorbers. Due to the high normal incident linear power density, i.e., $149 \mathrm{~W} / \mathrm{mm}$, the crotch absorbers encounter the most severe thermal and structural loads and generate large photon induced desorption gas loads. 6 Several crotch absorber geometries have been evaluated, both analytically and experimentally, with electron beam welder (EBW) beam testing. The experiments, using the EBW beams, evaluate thermal and structural performance, including deformation and fatigue due to the cyclic heating and cooling. The most promising crotch absorber 
geometry, the compound- $V$ as shown in Figure 3 , is being developed in detail. Inltial EBW beam test measurements agree well with predicted performance. Tests with photon beams will be conducted.

The density of desorbed gas will be high in the crotch areas, and high speed lumped pumping is provided in these regions. Lumped $220-1 / 5$ ion anc $1000-1 / s$ NeG pumps are employed to remove a large portion of the desorbed gases. The remaining gas permeating into the chamber is pumped by the distributed NeG pumps.

Distributed absorbers are located at the end of the straight sections following the upstream bending magnet sections in order to absorb the radiation that passes between the crotch absorbers and the positron beam. About $25 \%$ of the bending magnet radiation is absorbed by distributed absorbers. As a result, a significant amount of gases will be desorbed. As in the case of the crotch absorbers, most of the gases are trapped and pumped locally by lumped $220 \mathrm{l} / \mathrm{s}$ ion and $250 \mathrm{l} / \mathrm{s}$ NeG pumps.

The absorber vertical access flange penetrations result in discontinuities in the chamber cross section. In order to minimize the if effects due to such discontinuities, if screens are installed in these areas. The screens are made of aluminum sheets formed to correspond to the inner contour of the chamber and are provided with access slots. The slots provide pumping access for lumped pumps in the absorber locations while minimizing Wakefield effects on the beam and controlling if leakage from the positron beam. The screens are welded to the extrusion and have electrical continuity to the absorber structure through metallic spring finger contacts.

\section{PUMPING SYSTEM}

The use of integrated ion pumps employing the dipole fields is impractical in the storage ring, because only $24 \%$ of the ring is occupied with bending magnets. The vacuum system, therefore, relies on Non-evaporable Getter (NeG) strips as the primary source of distributed pumping in both the bending magnet and straight sections.

The $\mathrm{NeG}^{7}$ is a constantan strip coated with an alloy of $\mathrm{Zr} \mathrm{V}$ Fe. This alloy forms thermally stable chemical compounds with most of the active gases $\left(\mathrm{O}_{2}, \mathrm{~N}_{2}, \mathrm{CO}\right.$ and $\left.\mathrm{CO}_{2}\right)$, while the absorption of $\mathrm{H}_{2}$ is thermally reversible. To become effective as a pump, the strip is activated after pumpdown from atmospheric pressure. This procedure consists of heating the getter, which results in diffusion of the saturated surface layer into the bulk of the material. This heating also reduces the $\mathrm{H}_{2}$ content in the getter whenever the $\mathrm{H}_{2}$ dissociation pressure of the getter exceeds the $\mathrm{H}_{2}$ pressure in the vacuum 


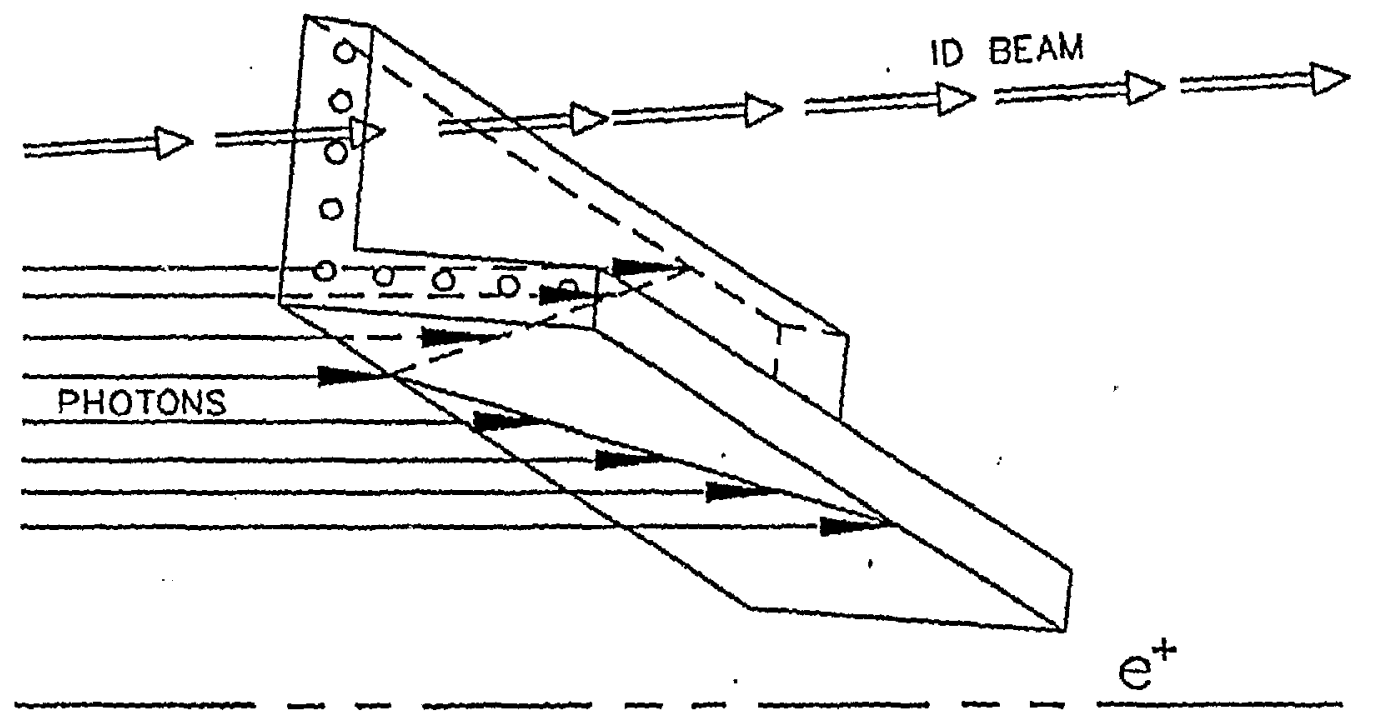

Figure 3

STORAGE RING COMPOUND-V SHAPE ABSORBER CONCEPT 
system. After activation, the strength of the gettering action depends on the temperature of the getter and on the amounts and molecular species of the gases that have been pumped. The pumping speeds immediately after activation are high, but they decrease progressively as the getter surfaces saturate. Before saturation, which is dependent on the gas composition, the NeG strip is conditioned by heating it again to restore the pumping speed. Heating of the NeG strips is done electrically and only during activation and conditioning. During normal pumping, the strips are not powered and operate at ambient temperature.

Two NeG strips (SAES ST707) are mounted in the chamber. Details of the NeG strip mounting are shown in Figure 4. The base mounting strip is constrained to the top and bottom antechamber walls within grooved tracks. The NeG strip is supported by stainless steel clips, which are attached to but electrically isolated from the base mounting strip by ceramic insulators. This mode of mounting the NeG strips is similar to that used in LEP.

As noted previously, lumped pumping is installed at photon absorber locations to pump the desorbed gas loads. The NeG strips do not pump $\mathrm{Cit}_{4}$ and noble gases such as Ar and He, therefore, ion pumps are required. The lumped pump distribution is as given by Table 3.

Table 3 Lumped Pumping

LOCATION

PUMPS

Section 1,

$30 \mathrm{l} / \mathrm{s}$ lon

End Absorber

Section 2 \& 4, Crotch Absorber $1000 \mathrm{I} / \mathrm{s}$ Lumped NeG $220 \mathrm{l} / \mathrm{s}$ Ion

Section 3 \& 5 , $250 \mathrm{l} / \mathrm{s}$ Lumped NeG Distributed Absorber $220 \mathrm{l} / \mathrm{s}$ Ion

Section 6, $220 \mathrm{l} / \mathrm{s}$ Ion End Absorber 


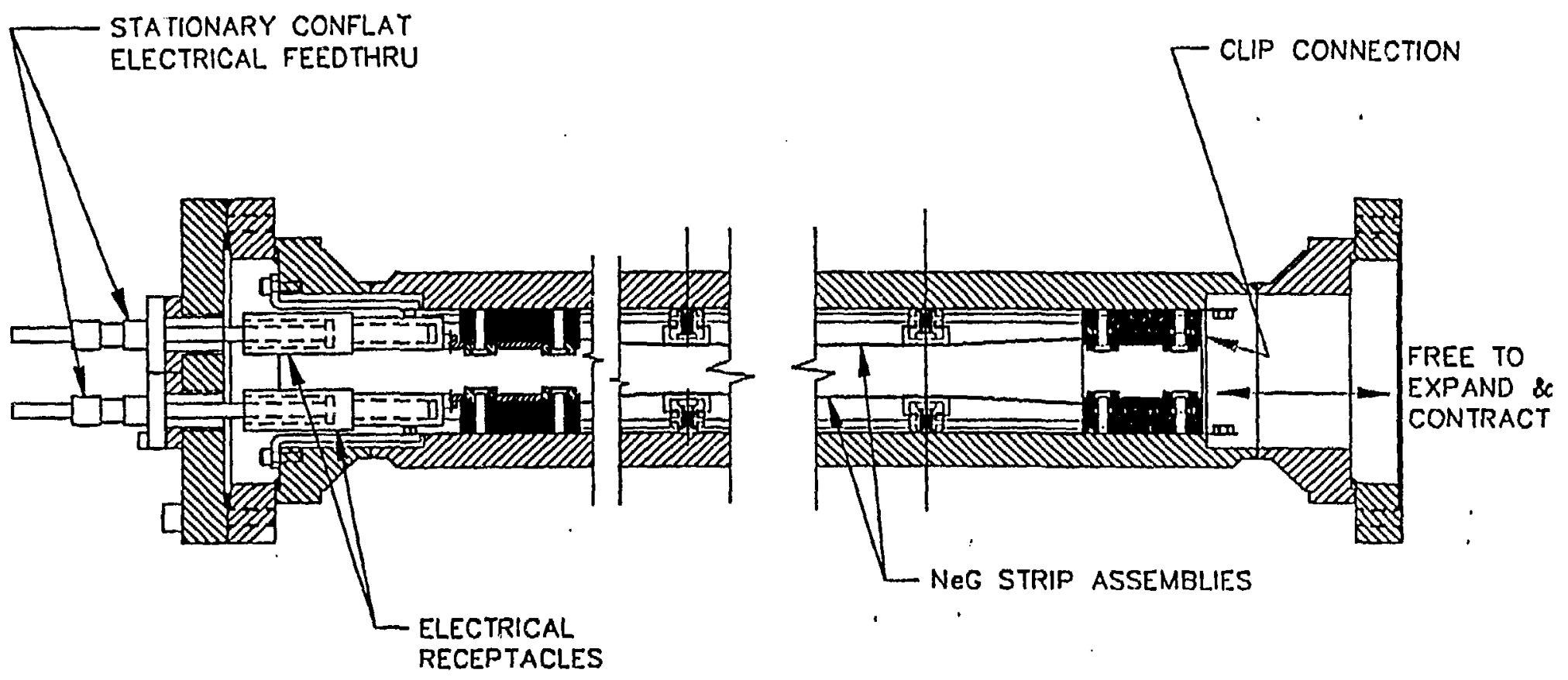

CROSS SECTION ALONG CHAMBER LENGTH

NeG Strip Mounting Details 
The ion pumps are started after bake-out and prior to isolation of the turbomolecular pumps as the activated NeG begins to dominate the pumping.

For initial pumpdown from atmospheric pressure, oil-free pumps evacuate the system to turbomolecular pump starting pressure. Turbomolecular pumps further reduce the pressure to ion pump starting pressures.

The roughing and turbomolecular pumps are integrated into a portable pumping station which is employed for sector pumpdown.

\section{VALVING}

The storage ring is equipped with valving for both transient and steadystate operations. The valves are of all metal construction, contain no organic materials and are bakeable to $300^{\circ} \mathrm{C}$.

Each sector is equipped with two ring isolation valves. These 4 inch if gate valves have an open valve geometry identical to the elliptical shape of the vacuum chamber and include if contacts that maintain elecirical continuity between the valve and it's mating connections.

Each experimental facility beam line is equipped with a 4 inch gate isolation valve.

Each sector is equipped with two 4 inch rignt angle pumpdown isolation valves.

Access for vacuum monitoring and control is through $11 / 2$ inch right angle diagnostic isolation valves.

\section{BELLOWS}

Lellows are installed between sections around the storage ring and between the experimental facility beamlines and the storage ring. The bellows are required for installation operations, alignment flexibility and bake/cool thermal motion tolerance. The bellows are formed from non-magnetic stainless steel and will be furnished with stainless steel flanges welded on each end. The positron beam chamber bellows will be equipped with rf liners to replicate the specific impedance of the elliptical beam chamber.

\section{FLANGES \& SEALS}

Flanges welded to the storage ring chamber are aluminum alloy $2219 \mathrm{~T}$ 851 Conflat flanges. They are coated on the sealing surfaces with a nitride or 
a carbide coating to increase knife edge hardness and prevent sticking of the seal.

All seals are metal seals. The aluminum Conflat flanges require an aluminum Conflat seal. These seals are made of A1050-H24 aluminum alloy that has been annealed.

\section{MONITORING}

lonization gauges are distributed around the storage ring. Since the ion pumps are situated in areas of highest desorption rates, their currents are monitored continuously and should provide adequate pressure measurements down to $1 \mathrm{nTorr}$. Gas analyzers, strategically placed around the ring and permanently connected to the control system, are used to monitor the composition of the residual gas. High-pressure gauges are installed in each sector to shut down the NeG power supplies in the event of a vacuum failure during activation and conditioning periods.

\section{SPECIAL FEATURES}

Transition connections are required in the positron beam channel between the storage ring and insertion device vacuum chambers. These chambers provide a gradual if transition between the two chambers that have different cross sections. The transitions are water cooled to absorb photon wall interaction heat loads and may incorporate NeG pumping to absorb a portion of local photon induced desorption gas loads. The preliminary design of a transition chamber is as given by Figure 5 .

Special chambers for beam injection, abort, and accelerator diagnostics will be incorporated in the storage ring. The designs of these chambers are being developed.

\section{PERFORMANCE ANALYSIS}

The analysis and calculations for gas loading for the storage ring of $2.26 \times 10^{-5}$ Torr.l/s has been previously reported. 2 As then reported, the desorption coefficient, $\eta_{\gamma}$ is $2 \times 10^{-7}$ mol/photon after 150 Ah of beam bombardment. This machine desorption efficiency is based on considerations of the major gas desorption occurring at discrete machine locations wherein the synchrotron radiation is absorbed on a relatively very small area of copper absorber accompanied by immediate intense pumping. Gas loading for a similar type geometry machine ${ }^{8}$ from experience with an electron storage ring 


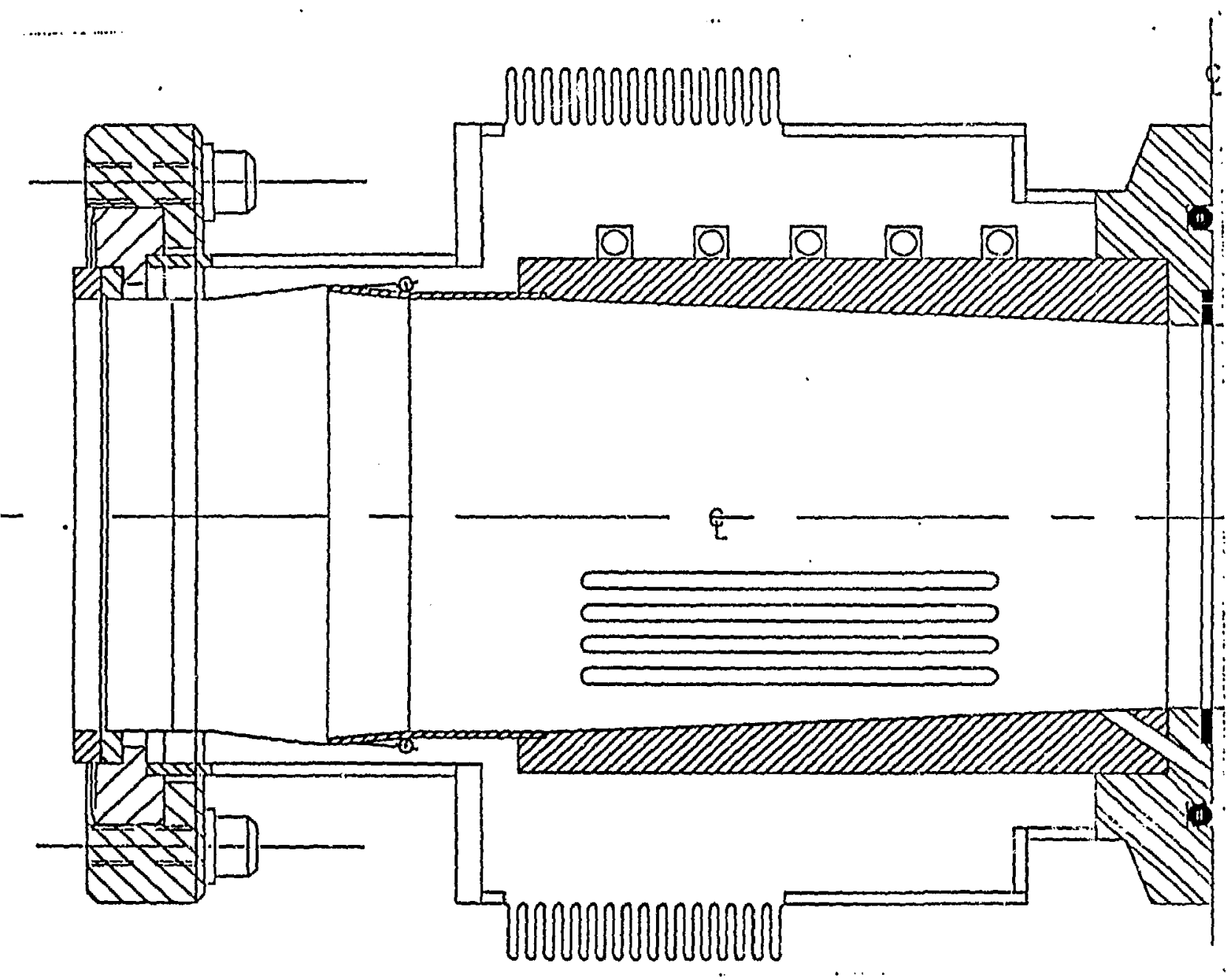

(CONCEPT LAYOUT) TRANSITION ASSEMBLY BETWEEN SECTION 5 AND INSERTION DEVICE 
after bakeout utilizes the expression for photon desorption coefficient as $\eta_{y}=$ $5 \times 10^{6} \mathrm{D}^{-.67} \mathrm{~mol} / \mathrm{photon}(\mathrm{D}=\mathrm{Ah})$ resulting in $1.7 \times 10^{-7} \mathrm{~mol} / \mathrm{photon}$ after 150 Ah.

Vacuum system performance analysis ${ }^{2}$ utillzes a finite-element-analysis computer program developed to calculate the pressure profile around the ring. 9,10 The storage ring sector is divided into 34 elements for which lengths, volume, conductance, pumping speed, and thermal and photon desorptions are the program input paramoters.

The predicted pressure gradlent through a sector determined by the program is shown in Figure 6. The curves dlsplay typical pressures after 1, 10 and $100 \mathrm{~A} \cdot \mathrm{h}$ of operation.

\section{DEVELOPMENT PROGRAM}

Beam Transport Sections 1-5 of a sector of the storage ring vasuum system Is under construction and will consist of the working vacuum system with diagnostic equipment. Construction of this facility provides a means for testing fabrication and assembly methods and evaluating vacuum performance at full scale.

The flve vacuum chamber sections were manufactured during the machining and weiding development program and include all system details. Chambers have been evaluated on an individual basis for vacuum integrity and base pressure. Base pressures of $4 \times 1^{-11}$ Torr, after baking, with ion pumps operating along with the NeG strips, have been achieved. (Details of these measurements are presented in a companion paper at this conference. ${ }^{10}$ ) Fuil sector tests will follow.

The achievement of reliable sealing of the Conflat jolnts after $150^{\circ} \mathrm{C}$ bakeout has not been consistent. A program is underway to improve this condition to system design requirements. Alternate sealing systems are being evaiuated.

Cleaning studies continue. The addition of ultrasonic agitation to the chamber extrusion cleaning process was included. In order to reduce machining time and thus cost assoclated with the currently planned dry machining, studies of machining with lubricants and subsequent cleaning have been made. Machining with lubricants is considered to be a viable option. Detergent cleaning of the $\mathbf{2 2 1 9}$ aluminum components, rather than solvent cleaning with its associated safety concerns, is being evaluated.

The alignment thermal stability of the chambers and supports subjected to multiple bake/cool cycles has been evaluated with two sections (Sections 1 and 2) connected under storage ring conditions. Initial results indicate that 


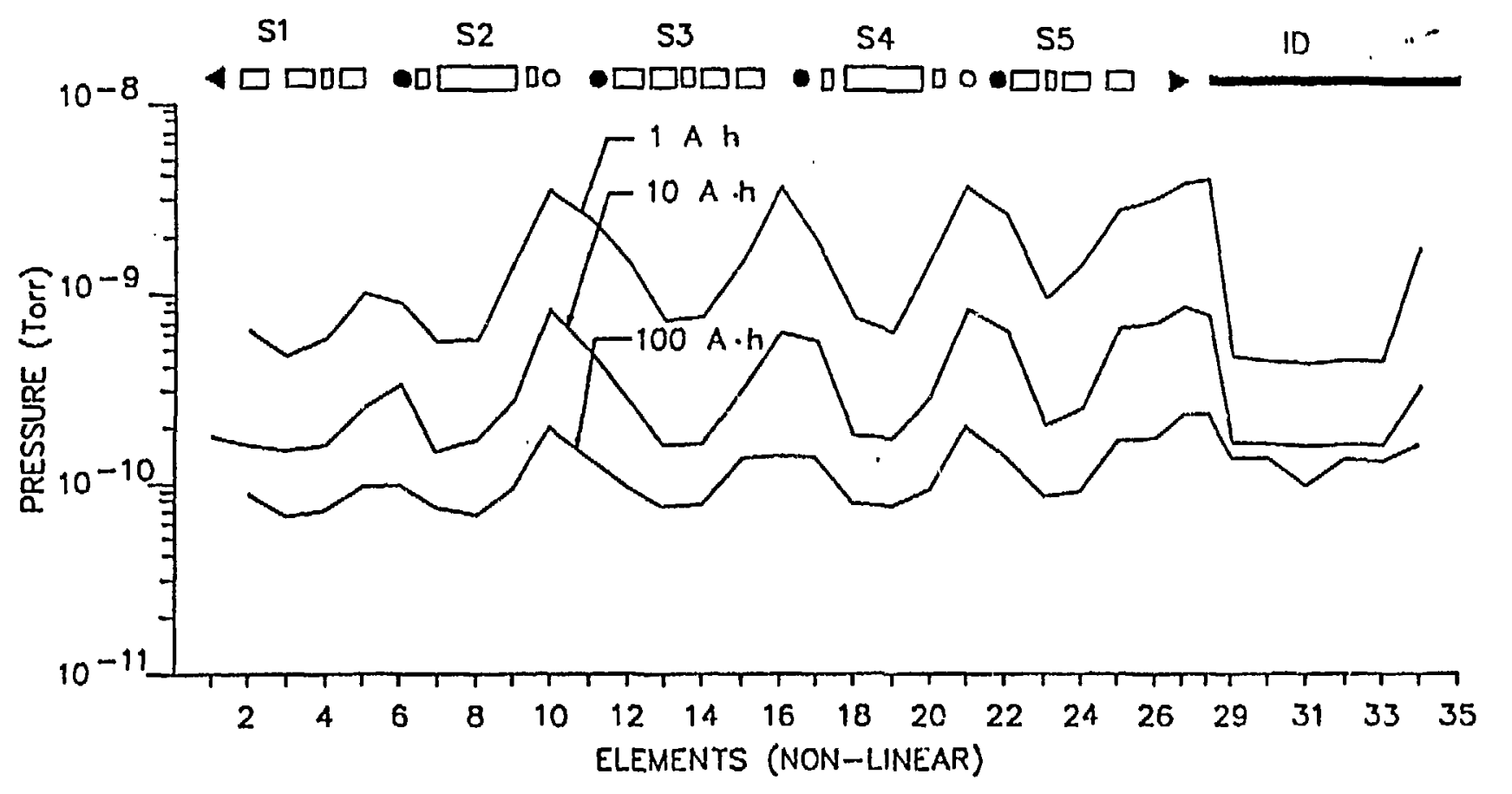

Figure 6

Storage Ring Pressure Gradient Profile for Prototype Sector 
position reproducibility is within the acceptable limits of beam position monitor alignment. The two section chamber tests are continuing. The evaluations will be expanded to a full sector configuration.

Chamber bakeout studies continue. A prototype hot water bake heat source has been assembled and is in operation. Candidate insulation systems are being evaluated.

Crotch absorber studies continue. Included are analysis, materials seiection, fabrication methods and performance measurements. Candidate absorber configurations are evaluated initially with EBW beams for thermal and structural response and fatigue effects. Final studies will be made with photon beams. These studies will include evaluations of the machine desorption efficiency in the crotch absorber regions.

Rf evaluations of the vacuum system continue. Included are impedance analysis and measurements of the chamber, absorber structure, absorber if screens, beam position monitors, ring isolation vaives, bellows and transition sections.

\section{CONSTRUCTION PROGRAM}

Design for construction is in its final stages.

Procurement of final designed items has been initiated.

A fabrication facility for chamber cleaning, welding, dimensional inspection, leak checking, assembly and vacuum performance measurements is being prepared. A pilot production run is planned to fabricate 1 or 2 sectors prior to the start of actual production activity. (Details of the fabrication plan are presented in a companion paper at this conference. ${ }^{11}$ )

\section{ACKNOWLEDGEMENTS}

The authors are grateful to Y. Cho, J. Galayda and R. Kustom for their encouragement and direction; to R. Blaskie, R. Ferry, K. Haggerty, $\boldsymbol{M}$. McDowell, R. Prien and E. Wallace for their contributions to the development program; to T. Gill and R. Piech for their contributions to the design; to A. Salzbrunn for the preparation of the manuscript; and to Y. Amer for editing.

\section{REFERENCES}

1. R. Wehrle, J. Moenich, S. Kim, and R. Nielsen, "Vacuum System for the Synchrotron X-Ray Source at Argonne," IEEE particle Accelerator Conf., Vol. 3 (1987). 
2. R. B. Wehrle and R. W. Nielsen, "Design for APS $7 \mathrm{GeV}$ Storage Ring Vacuum System at ANL": American Institute of Physics Conference Proceedings No. 171 American Vacuum Society Series 5, Upton, NY, 1988.

3. R. Wehrle, R. Nielsen and S. Kim, "Vacuum System Development Status for the APS Storage Ring". ANL, Argonne, IL.

4. A. G. Mathewson, "The Temperature and Time Dependerice of the Cleaning Efficiency of the Alkaline Detergent Almeco 28," LEP Vacuum Technical Note (January 15, 1986).

5. A G. Mathewson, "The Effect of Amklene on the Surface Composition of Extruded Al Alloy at Different Temperatures," LEP Vacuum Technical Note (1986).

6. M. Choi, "Development of APS Photon Absorber Design," APS Light Source Note. ANL, Argonne, IL, 1990 (In preparation).

7. B. Ferrario, L. Rosai, and P. Della Porta, "Distributed Pumping by NonEvaporable Getters in Particle Accelerators," IEEE Trans. Nucl. Sci., NS28, 3333 (June 1981).

8. B. A. Trickett, "The ESRF Vacuum System", American Institute of Physics Conference Proceedings No. 171 American Vacuum Society Series 5, Upton, NY, 1988.

9. J. F. J. Van Den Brand and A. P. Kaan, "Design Study of the Vacuum System for the E.S.R.F.", European Synchrotron Radiation Project Report, ESFP-IRM-61/84 (1984).

10. J. Kneuer, unpublished information (1985).

11. G. Goeppner, "APS Storage Ring Vacuum Chamber Fabrication," presented at the Topical Conference of the Vacuum Design of Synchrotron Light Source Conference, ANL, Argonne, IL, November 1990 to be published. 